believed to represent a sample of the very early Solar System, these anomalies are often interpreted as the result of an injection of freshly-synthesized material into the proto-planetary nebula just before, or while, it formed. Any glimpse of conditions in this elusive era is welcome, and fairly detailed review of some of the short-lived nuclides appears in this volume. chains synthesize the heavy elements beyond iron in the periodic table, but the actual sites where they occur remain rather uncertain. That the slow addition of neutrons occurs in evolved red giant stars is witnessed by the subsequent chemical peculiarity of their atmospheres, and the fast addition probably occurs near the cores of supernovae explosion of stars. It is still difficult to be sure of what reactions are most important in supplying the free neutrons, or of the conditions under which addition occurs. Indeed, it is argued in one of these essays that the rapid process is not really as fast as previously believed.

Nuclear astrophysics is an active field. This is a valuable book for those who know
The slow and rapid neutron capture

the basics of nuclear astrophysics and who want to find out about many of the current problems, but it is obviously not intended to be at a level suitable for a complete beginner. Many research workers will find it an essential source for Cameron's latest version (the last was in 1973) of his compilation of measured abundances in the Solar System. The book's topics are many, including hopes for detection of $\gamma$. rays from nucleosynthetic reactions and brief discussion of the early Universe, in addition to everything mentioned above. There is not a great deal included on fitting the nucleosynthesis processes into the overall evolution of galaxies, but to treat this fully would probably have required another volume, and the limitation is sensible.

Shining through the personal remarks in these essays is Willy Fowler's inspiring personality, and his practised adage that "Physics is fun!".

M.G. Edmunds is a Lecturer in the Department of Applied Mathematics and Astronomy, University College, Cardiff.

\section{Vision from the womb}

\section{F.W. Campbell}

\section{A Biography of the Eye: Development, Growth, Age.}

By R.A. Weale.

H.K. Lewis: 1982. Pp.366. £17.

PROFESSOR Weale introduces his book with "Some twenty years ago I wrote a survey of ocular aging [The Aging Eye, H.K. Lewis; 1963]. It aroused more interest than one would normally hope for with such a specialised study, and I have been urged ever since to write a new edition. The sheer boredom of reheating a meal put me off"'.

We should be grateful that he made this decision, for his new book embraces the changes that occur in the visual process from prenatal development until blindness and death. His Fig.1.1 typifies his project and teaching style where he plots percentage survival data for cafeteria tumblers, comparing annealed and toughened glass. $\mathrm{He}$ proceeds lucidly and succinctly to describe the reasons for the increasing age of the population. As he puts it: "Mathematically speaking, it is permissable to say that those who prolong life promote blindness".

In pursuing his theme, Weale has uncovered a large number of relevant and interesting references which will be unknown to the great majority of scientists. He blends them into a coherent and interesting account of the problem of blindness in the future which will encourage much-needed research in this area. The book quotes many new techniques for investigating visual performance not only in infants but also in adult blindness. The variety and quality of the figures and half-tone plates is superb. Many teachers will find them extremely useful in illustrating their lecture courses.

Recently there has been a plethora of books on vision, most of them saying the same thing. By contrast Professor Weale's book is quite unique and deals with almost everything the other books omit. It will also have a strong appeal to those non-visual scientists and clinicians interested in the aging process and eye development.

F.W. Campbell is Reader in Neurosensory

\section{Plants and scholars}

\section{Peter D. Moore}

History of Botanical Science.

By A.G. Morton.

Academic: 1982. Pp.475.

Hbk £19.80, \$45.50; pbk £8.80, \$21.50.

BOTANY, according to A.G. Morton, has its origin in magic and medicine. Since then, the cynic might argue, it has tended to move away from medicine. Its history, at least during the early stages, was quite independent of other sciences, even zoology, perhaps because of its association with agriculture. It is this independence which justifies the writing of a history of botany rather than one dealing with biology in general. Added to which, such a history has not been written in English for some 40 years. Physiology at the University of Cambridge.
History needs to be rewritten periodically, partly because it is constantly being added to, partly because historical research is constantly revealing new information and evidence concerning the past and partly because viewpoint and perspective are in constant flux as scientific thinking evolves. Our present view of Aristotle for example, may differ from the way Julius von Sachs regarded him.

Morton has not dwelt upon current developments in botany. In fact only 19 pages out of a total of 466 are devoted to the twentieth century, so one must look for other areas in which he has added to historical knowledge. One finds a freshness of approach in the weight Morton places upon certain concepts and the work of certain early botanists. Take Theophrastus, for example; Morton emphasizes the value of Theophrastus' concept of the adaptation of plants to their environment and regards him as the father of ecology. In his assessment of the work of the classical botanists of the ancient world, one is struck by the detail and scholarship of Morton's approach. The subtleties of the Greek language are well appreciated and frequently quoted by him.

Although the author makes full use of his knowledge of verbal nuances in the interpretation of developments in botanical concepts, I feel that he could have taken greater advantage of modern developments in botanical science in order to interpret early discoveries and notions. The assessment of the work of Dioscorides, for example, and its influence upon Islamic herbalism, makes a fascinating story which could have been made yet more vivid if it had been considered in the light of modern biochemical knowledge of the plants concerned.

The book develops along strictly chronological and historical lines rather than by topics, and this enables the author to present the development of botany in its contemporaneous intellectual environment. Occasionally, however, one feels that something is lost by separating botany so strictly from zoology; zoological analogies often played an important part in the development of botanical models, a point clearly illustrated by François Delaport in his analysis of the use of zoological analogies in eighteenth-century botany (Nature's Second Kingdom, published by MIT Press in 1982).

This book is a work of great care and scholarship and it traces in detail the emergence of philosophical concepts within the science of botany. It is a book which will delight the historian, but may leave the modern botanist just a little disappointed in that the concepts themselves are not always set out in ways which clarify their relevance to current botanical thought.

Peter D. Moore is Senior Lecturer in the Department of Plant Sciences, King's College, University of London. 